\title{
Knowledge and beliefs regarding cervical cancer screening and HPV vaccination among urban and rural women in León, Nicaragua
}

\author{
Hannah D Rees Corresp., 1 , Alexandra R Lombardo \\ Caroline G Tangoren \\ Linda M Niccolai ${ }^{3}$ \\ 1 Yale University, New Haven, Connecticut, United States \\ 2 Department of Health Policy and Management, Yale School of Public Health, New Haven, Connecticut, United States \\ 3 Department of Epidemiology of Microbial Disease, Yale School of Public Health, New Haven, Connecticut, United States \\ Corresponding Author: Hannah D Rees \\ Email address: hannah.rees@yale.edu
}

Sara J Meyers ${ }^{1}$, Vishnu R Muppala ${ }^{2}$

Background. In Nicaragua, cervical cancer is the leading cause of cancer-related death for women ages 15-44, yet access to the HPV vaccine is limited to those with financial resources to pay for it. Cervical cytology is provided free of charge in public clinics; however, only $10 \%$ of women receive Pap smears at the nationally recommended frequency. Previous studies have not investigated how beliefs regarding cervical cancer screening may differ for urban and rural populations in Nicaragua. Furthermore, no investigation has assessed Nicaraguan women's beliefs about a potential HPV immunization campaign. Given beliefs' influence on health behavior, we investigated the structural, sociocultural, and knowledge-based factors influencing women's beliefs regarding cervical cancer screening among urban and rural women in León, Nicaragua, and to assess acceptance of a potential HPV immunization program. Methods. Our sequential explanatory mixed-methods study consisted of two phases: (1) a close-ended questionnaire, followed by (2) a qualitative in-depth interview. Our quantitative sample contained 117 urban and 112 rural participants aged 18-49. We assessed beliefs regarding cervical cancer screening using a 22-item scale, with higher scores indicating screeningpromoting beliefs in simple linear and multiple linear regressions. Twenty qualitative interviews, exploring the sociocultural dimensions of knowledge and attitudes indicated by our quantitative findings, were conducted with a sample of 13 urban and 7 rural women aged 19-46. Results. The multiple linear regression indicates that greater knowledge of Pap smears, HPV, and cervical cancer is significantly associated with screening-promoting beliefs after adjusting for other relevant factors. There was no significant difference in screening knowledge and beliefs for urban and rural women. Four recurrent themes representing determinants of knowledge, beliefs, and attitudes regarding cervical cancer screening arose from interviews and built on quantitative findings: (1) women's 
embarrassment due to the intimate nature of the Pap smear and male gender of exam provider discourages screening; (2) women believe Pap smears and cervical cancer are associated with sexual promiscuity, and this association stigmatizes women with the disease; (3) knowledge of cervical cancer prevention is limited to those who regularly attend health centers; and (4) women find screening inconvenient, believing understaffed clinics increase patient wait time, limit time patients spend with clinicians, and delay Pap results. A fifth theme indicates (5) participants' acceptance of a potential HPV immunization program. Discussion. Future interventions should focus on increasing access to information about cervical cancer prevention for women who do not regularly attend health centers. Furthermore, our results suggest that if funding were allocated to make the HPV vaccine accessible in Nicaragua, it would be well received. 

vaccination among urban and rural women in León, Nicaragua 
25 ABSTRACT

27 Background. In Nicaragua, cervical cancer is the leading cause of cancer-related death for

28 women ages 15-44, yet access to the HPV vaccine is limited to those with financial resources to

29 pay for it. Cervical cytology is provided free of charge in public clinics; however, only $10 \%$ of

30 women receive Pap smears at the nationally recommended frequency. Previous studies have not

31 investigated how beliefs regarding cervical cancer screening may differ for urban and rural

32 populations in Nicaragua. Furthermore, no investigation has assessed Nicaraguan women's

33 beliefs about a potential HPV immunization campaign. Given beliefs' influence on health

34 behavior, we investigated the structural, sociocultural, and knowledge-based factors influencing

35 women's beliefs regarding cervical cancer screening among urban and rural women in León,

36 Nicaragua, and to assess acceptance of a potential HPV immunization program.

37 Methods. Our sequential explanatory mixed-methods study consisted of two phases: (1) a close-

38 ended questionnaire, followed by (2) a qualitative in-depth interview. Our quantitative sample

39 contained 117 urban and 112 rural participants aged 18-49. We assessed beliefs regarding

40 cervical cancer screening using a 22-item scale, with higher scores indicating screening-

41 promoting beliefs in simple linear and multiple linear regressions. Twenty qualitative interviews,

42 exploring the sociocultural dimensions of knowledge and attitudes indicated by our quantitative

43 findings, were conducted with a sample of 13 urban and 7 rural women aged 19-46.

44 Results. The multiple linear regression indicates that greater knowledge of Pap smears, HPV,

45 and cervical cancer is significantly associated with screening-promoting beliefs after adjusting

46 for other relevant factors. There was no significant difference in screening knowledge and beliefs

47 for urban and rural women. Four recurrent themes representing determinants of knowledge,

48 beliefs, and attitudes regarding cervical cancer screening arose from interviews and built on 
49 quantitative findings: (1) women's embarrassment due to the intimate nature of the Pap smear

50 and male gender of exam provider discourages screening; (2) women believe Pap smears and

51 cervical cancer are associated with sexual promiscuity, and this association stigmatizes women

52 with the disease; (3) knowledge of cervical cancer prevention is limited to those who regularly

53 attend health centers; and (4) women find screening inconvenient, believing understaffed clinics

54 increase patient wait time, limit time patients spend with clinicians, and delay Pap results. A fifth

55 theme indicates (5) participants' acceptance of a potential HPV immunization program.

56 Discussion. Future interventions should focus on increasing access to information about cervical

57 cancer prevention for women who do not regularly attend health centers. Furthermore, our

58 results suggest that if funding were allocated to make the HPV vaccine accessible in Nicaragua,

59 it would be well received.

60

61

62

\section{INTRODUCTION}

Cervical cancer is the second most common cancer among women in developing

64 countries, with approximately 445,000 new cases reported in less-developed regions in 2012 [1].

65 Over $80 \%$ of the burden of cervical cancer in the Americas is concentrated in Latin America and

66 the Caribbean, with mortality rates due to cervical cancer three times higher than in the United

67 States and Canada [2]. In the Americas alone, cervical cancer takes the lives of 35,700 women

68 each year, and is projected to increase to 51,500 annually by 2030 due to an increase in life

69 expectancy and population growth [3]. The vast majority of cases of cervical cancer are caused

70 by persistent infection with specific strains of human papilloma virus (HPV) [13]; vaccination

71 against HPV-16 and -18 can prevent nearly $70 \%$ of cases of cervical cancer [13]. In addition,

72 screening through the use of cervical cytology is an extremely effective method to identify pre-

73 cancerous lesions and prevent the development of cancer [14]. 
In Nicaragua, cervical cancer is the leading cause of cancer-related death for women ages

75 15-44, with an age-standardized mortality rate nearly double the global average [4]. Nicaragua

76 has the highest incidence rate of cervical cancer in Central America and the highest mortality

77 rate in all of Latin America, with 31 cases and 14 deaths per 100,000 women, respectively [4, 5].

78 More than 900 new cases of cervical cancer are diagnosed per year in Nicaragua [4]. Despite the

79 immense burden of cervical cancer in Nicaragua, access to the HPV vaccine is limited to those

80 who have the financial resources to pay for the vaccine [4]. Thus, screening with cervical

81 cytology remains the primary means of prevention [4].

82 In Nicaragua, cervical cytology is recommended every three years following three

83 consecutive normal annual Pap tests for women aged 25 to 64, though women outside of this age

84 range are eligible to receive the exam [14]. Cervical cytology is provided free of charge in the

85 public sector in Nicaragua; however, only $10 \%$ of women receive Pap smears at the frequency

86 recommended by national guidelines [4,14]. Several studies have examined the factors that

87 contribute to low rates of cervical cancer screening in Nicaragua and other Latin America

88 countries. An investigation conducted in 2002 in the department of Rivas, Nicaragua, found that

89 inadequate cervical cancer screening among women was correlated with low educational level,

90 exclusive use of public health services, and limited knowledge of prevention and symptoms of

91 cervical cancer [6]. Additionally, women with a lack of previous medical problems, who faced

92 economic barriers, were less likely to seek out screening [6]. A review of five qualitative studies

93 [7] conducted in Venezuela, Ecuador, Mexico, El Salvador, and Peru indicated that barriers to

94 cervical cancer screening included lack of access to quality health services, lack of privacy and

95 comfort during screening, and poor service delivery. The review noted that rural women often

96 had longer travel time to reach health care facilities and receive Pap results, and possessed a 
97 greater fear of the social acceptability of receiving a Pap smear when compared to urban women;

98 however, no study has addressed potential differences among urban and rural women in

99 Nicaragua [7]. Furthermore, past studies have addressed the sociocultural barriers to the rollout

100 of the HPV vaccine in select low and middle-income countries [13], though none has assessed

101 women's beliefs about a potential HPV immunization campaign in Nicaragua - data that could

102 be integral to the creation of a national vaccination program.

103 In addition to identifying structural factors limiting cervical cancer screening, the review

104 highlighted beliefs, such as a general fear of cancer, anxiety while waiting to receive screening

105 results, and stigma surrounding Pap smears, that contributed to low rates of preventive screening

106 [7]. This finding aligns with the Health Belief Model (HBM), one of the most widely applied

107 frameworks for health behavior [19]. This model indicates that perceived susceptibility and

108 severity of disease, and perceived benefits and barriers to health-promoting action, determine

109 health behavior [19]. Given the influence of beliefs on cervical cancer screening, past studies

110 have drawn upon the HBM to assess beliefs as a predictor of cervical cancer screening behavior

$111[15,16,17]$.

112 Accordingly, we sought to examine the structural, sociocultural, and knowledge-based

113 factors that may influence women's beliefs regarding screening for cervical cancer in León,

114 Nicaragua. We sought to compare these results between urban and rural women in the region,

115 and hypothesized that urban women would hold stronger screening-promoting beliefs compared

116 to rural women. In addition, we aimed to assess the views of both urban and rural women on the

117 potential introduction of the HPV vaccine in the region. Our study employed a mixed methods

118 strategy to expound upon our quantitative findings with in-depth interviews, allowing us to

119 assess the determinants of cervical cancer screening and the underlying sociocultural factors that 
120 shape perceptions of the disease. Findings from this study can be used to guide future cervical

121 cancer prevention efforts tailored to the needs and perspectives of urban and rural women in

122 Nicaragua.

123

124

125

126

127

\section{MATERIALS \& METHODS}

\section{Study design and sampling strategy}

The study design was sequential explanatory mixed-methods conducted over the course

128 of eight weeks from June to August of 2016, and consisted of two phases: (1) a close-ended

129 questionnaire administered in person by researchers for the first six weeks, followed by (2) a

130 qualitative in-depth, face-to-face interview for the final two weeks. The quantitative component

131 of the study was conducted first to assess potential gaps in knowledge and general beliefs

132 regarding HPV, cervical cancer, and screening practices. It also examined acceptance of a

133 potential HPV immunization campaign. The preliminary quantitative results influenced the

134 creation of the open-ended discussion guide, which sought to elucidate sociocultural dimensions

135 of knowledge and attitudes about HPV, cervical cancer, screening practices, and acceptance of

136 HPV immunization that might further explain our quantitative findings.

137 Participants were recruited from three urban health centers and three rural health posts in

138 León, the second largest city in Nicaragua [8], for both phases of the study. The health centers

139 granted us permission to speak with women regarding participation in the study while they

140 waited to be seen by a health care provider. We approached all adult women to participate in the

141 study. Women eligible to participate in the quantitative component of the study were Spanish-

142 speaking, aged 18-49, and had no history of cervical cancer or a hysterectomy. The same

143 eligibility criteria were applied for participants in the qualitative component of the study;

144 however, women with a history of cervical cancer or a hysterectomy were eligible to participate. 
145 As the questionnaire measured general knowledge of HPV and cervical cancer, women with a

146 history of the disease could have potentially biased the results with knowledge gained from their

147 specific experiences. One woman with a history of cervical cancer provided valuable insight, and

148 was included in the qualitative sample. Women who had completed the quantitative survey were

149 excluded from the qualitative component of the study.

150

151

152

153

154 from both the Cervical-Cancer-Knowledge-Prevention-64 (CCKP-64) [9] and the Carolina HPV

155 Immunization Measurement and Evaluation Project (CHIME) questionnaires [10]. Nicaraguan

156 professors of medicine from National Autonomous University of Nicaragua (UNAN), León,

157 aided in the development of the questionnaire to ensure its cultural competency and validity. The

158 final version of the questionnaire consisted of five sections. The first section was comprised of

159 general demographic questions. Section two covered knowledge and beliefs regarding Pap

160 smears, as well as past experiences with the exam. The third and fourth sections assessed

161 knowledge and beliefs regarding HPV and cervical cancer, respectively. Relevant questions were

162 selected from CCKP-64 [9] to assess knowledge of HPV and cervical cancer in these sections.

163 The fifth section addressed acceptance of a potential HPV immunization campaign, utilizing

164 questions from the CHIME questionnaire [10]. The questionnaire was piloted with 50 women at

165 the three urban clinics. Modifications were made to the instrument to increase the clarity and

166 specificity of selected questions. All research procedures were approved by the Institutional

167 Review Board at the Yale School of Medicine (HSC \#1603017360) and UNAN, León.

168 The questionnaire was administered over a period of six weeks in health center waiting

169 areas during their opening hours. All questionnaires were anonymous and administered by a 
170 member of the research team, who read all instrument questions and response choices to each

171 participant after achieving informed, verbal consent. Although the sample was a convenience

172 sample, participants were diverse in socioeconomic status, age, and urban/rural location of

173 residence. We attempted to survey every eligible participant at the clinics each day, however we

174 approximate that only $80 \%$ of those asked to participate completed the survey. One urban health

175 center was larger than the others, but response rates were similar across health centers. After

176 eliminating incomplete surveys from our sample, the final yield rate was 57\% (Figure).

177 Incomplete surveys arose from participants leaving the health center before completing the

178 questionnaire.

179

Outcome variable

183 participants' beliefs regarding physical and emotional discomfort associated with Pap smears,

184 perceived safety of the exam, the amount of time it takes to receive the exam and results, the

185 relationship between Pap smears and sexual promiscuity, frequency of screening, comfort

186 receiving a Pap from a male clinician, and perceived likelihood of being affected by cervical

187 cancer in the future (Appendix B). Questions that involved four-level Likert responses

188 (somewhat agree, strongly agree, somewhat disagree, strongly disagree) were dichotomized into

189 two responses (i.e. Pap tests are safe: $1=$ agree, $0=$ disagree). Negative statements were

190 reverse coded to ensure only screening-promoting beliefs increased one's belief score (i.e. Pap

191 tests are painful: $0=$ agree, $1=$ disagree). The variable index was created as a simple

192 summation of quantified answers to belief questions (range, 0-22), so that a higher belief score

193 corresponds with screening-promoting beliefs. 
195

196

197

198

199

200

201

202

203

204

205

206

207

208

209

210

211

212

213

214

215

216

217

218

219

\section{Explanatory variables}

Knowledge was assessed through the creation of a knowledge index, a summation of 9 questions (range, 0-9) that surveyed knowledge of Pap smears, HPV, and cervical cancer (Appendix B). A higher score corresponds to greater knowledge of these topics. Questions that involved a four-level Likert scale (somewhat agree, strongly agree, somewhat disagree, strongly disagree) were dichotomized into two responses (i.e. You do not know where to receive a Pap smear: $0=$ agree, $1=$ disagree). Other questions were dichotomous in nature, and coded accordingly (i.e. Can HPV cause cervical cancer? $1=y e s, 0=n o$ ). The survey item that tested knowledge of the requirements of a Pap smear (What are the requirements to have a Pap smear?) was coded such that each correct response was awarded 0.25 points (not menstruating, not using a vaginal douche before exam, not applying vaginal cream, medication, or suppository before exam, not having intercourse three days before exam), while the incorrect response (there are no requirements) was coded to be 0.

\section{Covariates}

Covariates included region of residence, education, income, age, and direct contact with an individual with cervical cancer. Region of residence was a binary variable (rural $=1$, urban $=$ 0 ). Education was represented by 5 dummy variables, with postgraduate education being the reference level (none or preschool, some or complete primary school, some or complete secondary school, some or complete university, postgraduate). Income was indicated by 4 dummy variables, with living comfortably being the reference level (poor, just getting by, living comfortably, rich). Age was a continuous variable. Direct contact with an individual with cervical cancer was a binary variable. If the participant had known an individual that had been 
220 diagnosed with cervical cancer, it was coded as 1 . If the participant did not know someone with

221 cervical cancer, or reported not knowing if she knew someone, it was coded as 0.

222

223

224

225

226

227

228

229

230

231

232

233

234

235

236

237

238

239

240

241 The interviews also included questions evaluating the experiences of women with HPV and

242 cervical cancer, and how the participant makes decisions regarding her sexual health. Finally, the

243 guide included questions to assess views on the HPV vaccine. The discussion guide was piloted

244 with five women at urban and rural clinics to improve interview technique and identify the most

245 effective prompts and probes. 
247 health centers and three rural health posts during their opening hours. Interviews were conducted

248 with women waiting to be seen by health care providers, out of earshot of other patients. The

249 researcher provided each participant with a written and verbal description of the details of the

250 study, and verbal consent was received from each participant. Interviews were anonymous,

251 audio-recorded, and only accessible to the researchers. We continued to interview women until

252 the point of theoretical saturation, i.e., when successive interviews produced no additional

253 concepts [11], which occurred after 21 interviews.

254

255

256

257

258

259

260

261 Research team members coded three interviews independently using the preliminary code

262 structure. Modifications to the code were made after the discrepancies in coding were resolved

263 by negotiated consensus. This process was repeated three more times before the code structure

264 was finalized. Each interview was coded by two researchers using Dedoose qualitative software

265 to organize the data, and discrepancies were resolved through in-depth discussions [11]. Themes

266 were derived from the detail-rich experiences of participants, which were discussed amongst

267 research team members. Five main themes emerged from the data and were finalized through

268 negotiated consensus [11]. 
272

273

274

275

276

277

278

279

280

281

282

283

284 income level to be "poor" compared to urban women (27\%). On average, rural women reported

285

286

287

288

289

290

291

292

293

294

295

296

\section{RESULTS}

\section{Quantitative sample description}

The characteristics of both the urban $(n=117)$ and rural $(n=112)$ survey respondents are presented in Table 1. Study participants had a mean age of 28.1 (range 18-49). More than half of the participants completed some or all of secondary school $(71 \%)$ in both the urban $(85 \%)$ and rural $(56 \%)$ populations. Significantly more women began or completed a university or postgraduate degree in the urban population (37\%) than in the rural (13\%). Most women who participated in the survey were married or in a domestic partnership (69\%) in both the urban $(62 \%)$ and rural populations (77\%). Most participants did not possess health insurance (89\%). Although a similar fraction of urban (52\%) and rural (53\%) participants reported their household income level to be "just getting by," a larger percent of rural women (35\%) described their traveling 7 minutes more to the health center than urban women. The majority of the women who participated in the study had previously received at least one Pap smear $(89 \%)$ in both the urban $(85 \%)$ and rural $(92 \%)$ populations. Data indicate that $80 \%$ of women at the health centers had received a Pap smear within the past year, with $37 \%$ of women screened within the past 3 months (Table 2). In both the urban and rural populations, the majority of women had been screened within the past year (Table 2).

\section{Qualitative sample description}

Our qualitative in-depth interview sample included 20 participants, 13 urban women and 7 rural women. Though only 14 participants reported their specific age, the range was wide (1946), with a mean of 32 years. Four recurrent themes representing determinants of knowledge and beliefs regarding cervical cancer screening arose from the interviews, as well as a fifth theme 
297 indicating participants' support of a potential HPV immunization program. Quantitative data

298 from the surveyed population support these findings.

299

300

302

303

304

305

306

307

308

309

310

311

312

313

314

315

316

317

318

319

320

321

322

323

324

325

326

327

Theme 1: Embarrassment associated with intimate nature of Pap smear and gender of exam provider

Participants indicated that some women are unlikely to have Pap smears as a result of the embarrassment and shame associated with the intimacy of the exam. Although some women have Pap smears to promote their health, others are too embarrassed to do so regularly. One woman described the shame she felt when receiving a Pap, and why she continues to regularly have the exam:

Many [women] like the Pap because they want to be healthy, because health is life, but others do not because it causes them embarrassment...they say "the doctor will check me out down there, and I don't like that"... I let [my shame] go, but it still causes me embarrassment, I still turn my face to the side. I feel this way because there are doctors touching me for the test, and although it shames me, I have to do it because it's for my health. (Participant 16, urban, aged 37 years)

Many women described their emotional discomfort with having a male provider performing their Pap smear. One woman described why she prefers having a Pap performed by a female provider: Emotionally, it's better with a woman [doctor] because with a man, [a Pap test] is more intimidating and you can't completely relax. While with a woman, she already knows what our parts are like, but the man only knows his parts and whatever he's studied of ours. (Participant 14, urban, aged 24 years)

Results from the quantitative survey (Table 3) support this finding, as more than $70 \%$ of women reported feeling uncomfortable receiving a Pap from a male clinician. Although the majority of women prefer to have a female clinician perform their exam, women spoke of having little choice over the gender of their provider at public health centers. The only women guaranteed to have a female clinician perform their Pap are those who attend private clinics, which provide services that are unaffordable for many women in the population. 

women with the disease

A recurrent theme was the belief that Pap smears and cervical cancer are associated with sexual promiscuity, and this association stigmatized and isolated women with cervical cancer in the region. Quantitative data (Table 3) illustrated a perceived relationship between cervical

334 cancer screening and sexual promiscuity, as $54 \%$ of the population believed that teenage girls

335 who receive Pap smears will be more likely to have sexual relations. This belief was more 336 prominent among rural women (63\%) than urban women (44\%). Participant 18, a 26-year-old,

337 urban woman spoke of Nicaragua as being a "conservative culture" with a "taboo

338 about...information related to sexuality," especially in rural regions, where "they are more 339 reserved."

340 Qualitative findings further developed this theme, linking the stigmatization of cervical

341 cancer to the isolation experienced by women with the disease. Participant 15, a 46-year-old,

342 urban woman described living with cervical cancer to be like "living alone." Another woman

343 spoke of the isolation experienced by her aunt with cervical cancer, who did not tell her family

344 about her cancer until five days before she died from the disease. The woman revealed the impact

345 her aunt's experience had on her own perception of the importance cervical cancer screening: [My family] never thought any of these diseases existed until [my aunt's cervical cancer] happened and we suffered... what my aunt did of not talking about [her cervical cancer] was really bad because we were ignorant that she was suffering. For this reason it is good to discuss it and go get tested. I would say that women should get checked and have a Pap to detect disease or infection on time.

(Participant 19, urban, aged 23 years)

354 association existing between cervical cancer and HPV, a sexually transmitted infection that

355 serves as an indicator of sexual promiscuity in the community. One participant depicted the 356 discrimination faced by women with cervical cancer: 

suffer from it, and take to talking about the people who have these problems. In reality it's a problem that we could all get, because even if a woman stays home protecting herself and taking care of herself, she doesn't know if her husband is out on the streets with someone else, so because of this many women stay quiet.

364 This woman indicated that a root cause of the discrimination against women with cervical cancer

365 is the association of the disease with sexual promiscuity. She suggests that a woman who is not

366 sexually promiscuous but acquires HPV from her partner can still be blamed for developing

367 cervical cancer. As a result of the association of cervical cancer with sexual promiscuity, women

368 with the disease fear judgment from their peers and therefore do not speak of their experience

369 with cancer.

Theme 3: Knowledge of cervical cancer prevention limited to those who regularly attend health centers

Women reported their main source of knowledge regarding cervical cancer prevention to

374 be charlas, or brief health workshops presented by providers at the health centers. Participant 14,

375 a 24-year-old, urban woman stated that people in her community go specifically to health centers

376 to receive "primary information" on these topics. Other women claimed that cervical cancer was

377 only discussed in their community within the context of the health center. As a result, women

378 who do not regularly seek care at these clinics have limited access to information regarding

379 cervical cancer screening.

380 The results from the multiple linear regression (Table 4) indicate that greater knowledge

381 of Pap smears, HPV, and cervical cancer was significantly associated with screening-promoting

382 beliefs, which measures a woman's likelihood of being screened based on her responses to 22

383 belief questions (Appendix 1). The multiple linear regression indicated that knowledge $(\beta=0.73$,

$384 \mathrm{p}<0.001)$ was a significant predictor of belief score, even after adjusting for having had 
385 personal contact with cervical cancer, region of residence, age, education, and income. Region of

386 residence, however, was not a significant predictor of screening-promoting beliefs.

387 The significance of knowledge in predicting women's beliefs was supported by

388 qualitative data, which illustrated the self-efficacy and screening-promoting beliefs of women

389 with knowledge of cervical cancer and screening practices:

390

391

392

393

394

395

396

[The word "cancer"] is startling but I believe that yes, if they detect [cervical cancer] on time as I have my [regular Pap], I know that they can treat it with medicine. But if it is already too late, it is alarming that the consequence are already grave.

(Participant 14, urban, aged 24 years)

In contrast, women who knew less about cervical cancer held abstract fatalistic views of the

disease, rather than prevention-oriented beliefs:

397

398

399

400

401

402

403 screening practices may increase the likelihood of a woman holding screening-promoting beliefs.

404 Although health centers are the primary source of information regarding cervical cancer and Pap

405 smears, quantitative data indicate that $26 \%$ of women who were surveyed at health centers were

406 unsure of the health benefits or purpose of a Pap smear (Table 3).

407 Theme 4: Inconvenience of screenings at understaffed clinics increases patient wait time, 408 limits time patients spend with clinicians, and delays Pap results

409 Women perceived screening to be inconvenient as they reported waiting for several hours

410 before being seen by a clinician. Participants also indicated that clinicians were often too busy to

411 spend a sufficient amount of time with each patient:

412 
413

414

415

416

417

418

419

420

421

422

423

424

425

426

427

428

429

430

431

432

433

434

435

436

437

438

439

440

441

442

For example, today I came in twice. The first time took two hours, and I couldn't get in because it turned out that the doctor was attending to pregnant women, and there were even more behind schedule... [which causes] the doctor to occasionally attend to patients hurriedly... right now there's one doctor. There are two that are missing. I don't know if they are on vacation or what, and that in part affects the general manner of the patients, because one gets restless and people get angry.

(Participant 17, urban, aged 47 years)

Other participants explained that they were unlikely to receive regular Pap smears due to the amount of time it takes to be seen at the health center. One woman admitted that she should be having Pap smears more regularly, however was unable to spend hours at the health center:

I have not had the time [to receive a Pap] because of work, but if I were to dedicate the day to see the doctor, I would get the results...

(Participant 20, urban, aged 38 years)

In addition, over $63 \%$ of women reported having to wait a long period of time to receive the

results from their Pap smear (Table 3). Women believed regular screenings were inconvenient

due to long patient wait times, limited time with clinicians, and delayed Pap results.

\section{Theme 5: Support of potential HPV vaccination program}

Participants expressed positive attitudes towards and acceptance of a potential HPV

vaccination program. Although the majority of women interviewed had limited knowledge of the

vaccine, every woman supported its use after learning of its ability to protect against cancer-

causing strains of HPV. When speaking about the HPV vaccine, one woman stated:

I've heard about it but I barely [had] any complete information ...[the vaccine] would be really good because we are trying to fight [HPV] and that way we would be vaccinated against it.

(Participant 19, urban, aged 23 years)

Nearly $98 \%$ of urban and rural women said that they would be likely or very likely to give their

daughter the HPV vaccine within the next year if it were to be made free and available at the

health centers (Table 3). Participant 7, a rural woman, stated that she would vaccinate her 
443 daughter as it would "save her" from HPV and cervical cancer. Another woman explained that

444 even if she had to pay for the vaccine, she would try and provide it for her daughter:

445

446

447

448

449

450

451

452

453

454

455

456

457

458

459

460

461

462

463

464 suggests that those with the financial means to receive Pap smears at private clinics with female

465 providers may be more likely to seek regular screening than those limited to receiving care at

466 public health centers. This finding builds upon previous literature that cites the exclusive use of

467 public health services to be a contributing factor to low rates of cervical cancer screening in

468 Rivas, Nicaragua [6]. In addition, our findings align with a review of qualitative studies 
469 conducted in Venezuela, Ecuador, Mexico, El Salvador, and Peru that suggest that poor service

470 delivery, such as long wait time to receive a Pap, may also contribute to low rates of screening in

471 Nicaragua [7].

472 Our results indicate that there was no significant difference in the attitudes and beliefs

473 regarding cervical cancer screening for urban and rural women, as region of residence was not a

474 significant indicator of screening-promoting beliefs in the multiple linear regression. Thus, the

475 data was not consistent with our hypothesis that urban women would hold stronger screening-

476 promoting beliefs than those held by rural women. A potential explanation of this result arises

477 from our qualitative finding that most women in León learn about HPV and cervical cancer

478 screening in health centers rather than from the general education system. Consequently, the

479 increased amount of time urban women spend in school compared to rural women would not

480 significantly affect their knowledge of the disease and screening. As knowledge is a significant

481 predictor of holding screening-promoting beliefs, urban and rural women who have access to

482 health centers may hold similar screening-promoting beliefs regardless of their region of

483 residence.

484 Our findings must be interpreted in light of the limitation that a convenience sample was

485 used in which participants were attendees of one of six health centers. We hypothesize that the

486 convenience sample can, in part, explain our finding that the majority of both urban and rural

487 women had received Pap tests within the past year. This finding stands in contrast to literature

488 indicating that only $10 \%$ of women receive Pap smears at the nationally recommended frequency

$489[14]$. We conjecture that the women who participated in the study accessed the health centers and

490 were more likely to receive information regarding screening than their counterparts without

491 regular access to the health centers, and thus, were more likely to be screened. Consequently, 
492 future studies could utilize a random sample to better understand factors that limit screening

493 among women who do not regularly access the health centers, and how knowledge, beliefs, and

494 screening frequency may vary between urban and rural populations. An additional limitation of

495 our study was that we did not acquire an exact response rate for the quantitative sample;

496 however, we were able to make an accurate estimate on the number of women who were eligible

497 and willing to participate in the study, and calculated a precise final yield rate based upon the

498 number of completed surveys (Figure). It is also important to note the potential limited

499 generalizability of our findings, which should be applied to other regions with caution. However,

500 we note that our findings are applicable to both urban and rural populations of León, suggesting

501 that they may be favorably applied to populations of varying demographics.

502 Despite its limitations, our research sheds light on several policy and practice

503 implications that can reduce the incidence of cervical cancer in Nicaragua - the country with the

504 highest cervical cancer mortality rate in Latin America [5]. As knowledge was significantly

505 associated with screening-promoting beliefs, future interventions should focus upon increasing

506 access to information regarding cervical cancer prevention for women who do not regularly

507 attend health centers. A program evaluation conducted in 2005 concluded that a partnership

508 between local NGOs and the Nicaraguan Ministry of Health successfully delivered quality

509 screening and health education programs through the use of mobile clinics in Nicaragua's rural

510 North Atlantic Autonomous Region [12]. The results from our investigation indicate the

511 importance of expanding similar education programs throughout the country, as increased

512 knowledge of cervical cancer is significantly associated with increased screening-promoting

513 beliefs. Furthermore, our results indicate that over a quarter of women surveyed at the health 
514 centers were unsure of the health benefits of a Pap smear (Table 3), indicating that the

515 educational capacity of the health centers can also be improved.

516 Though women described the stigma and embarrassment associated with screening, the

517 majority of participants had received a Pap smear within the last year (Table 2). Qualitative data

518 indicated that some women considered the potential health benefits of screening to outweigh the

519 shame they associated with the exam. This finding aligns with the Health Belief Model (HBM),

520 which indicates that perceived benefits and barriers to a health behavior, along with perceived

521 susceptibility and severity of disease, affect an individual's action to prevent illness [19]. Thus,

522 knowledge of the benefits of screening encouraged women to receive Pap smears despite the

523 negative attributes they associated with the exam. Consequently, we suggest that future

524 education campaigns focus upon the health benefits of regular screening as an effective means of

525 encouraging Pap smears in the region.

526 Furthermore, educational efforts should target additional components of the HBM,

527 including perceived barriers to screening and perceived susceptibility to HPV and cervical cancer

528 [19]. Our findings indicate that beliefs such as embarrassment associated with the intimate nature

529 of screening, as well as an association of Pap smears and cervical cancer with sexual

530 promiscuity, discourage routine screening. By emphasizing the medical importance of screening

531 and the prevalence of HPV and cervical cancer, educational efforts could mitigate perceived

532 barriers to Pap smears and lessen the stigma surrounding HPV, cervical cancer, and screening.

533 This investigation is the first documented assessment of potential acceptance of an HPV

534 immunization program in Nicaragua. Five Latin American countries with lower incidences of

535 cervical cancer than Nicaragua - Mexico, Panama, Colombia, Peru, and Argentina - all include

536 the HPV vaccine for girls in their national immunization programs [5, 13]. Though the HPV 
537 vaccine can provide health benefits for both girls and boys, the predicted cost-effectiveness for

538 vaccinating boys is limited when vaccination coverage for girls is over 50\% [18]. Thus, national

539 HPV immunization programs in Latin America have only targeted girls, and we focused our

540 assessment on the potential acceptance of the vaccine for girls in León. Our results reveal

541 overwhelming acceptance of an HPV immunization program, which has the potential to prevent

542 nearly $70 \%$ of cases of cervical cancer [13]. Our results suggest that if funding were allocated to

543 make the HPV vaccine accessible in Nicaragua, it would be well received and utilized to

544 decrease the incidence of cervical cancer in the country.

545

546 ACKNOWLEDGMENTS

547 The authors thank Dr. William Ugarte of UNAN, León for his guidance throughout the project,

548 as well as the staff at the health centers in which we conducted the investigation. We also

549 acknowledge and appreciate the time participants dedicated to partake in the study. Thank you to

550 Dr. Elizabeth Bradley and Dr. Amanda Brewster of the Yale Global Health Leadership Institute

551 for their help with the data analysis and formulation of the manuscript. 
553 1. Human papillomavirus (HPV) and cervical cancer (2016). World Health Organization. http://www.who.int/mediacentre/factsheets/fs380/en/

2. Capote Negrin, L. G. (2015). Epidemiology of cervical cancer in Latin America. Ecancermedicalscience, 9, 577. http://doi.org/10.3332/ecancer.2015.577

3. Cervical cancer in the Americas (2014). Pan American Health Organization. http://www.paho.org/hq/index.php?option=com_docman\&task=doc_view\&Itemid=270\& gid=17498\&lang=en

4. Bruni, L., Barrionuevo-Rosas, L., Albero, G., Serrano, B., Mena, M., Gómez, D., Muñoz, J., Bosch, F. X., \& de Sanjosé, S. ICO Information Centre on HPV and Cancer (HPV Information Centre). Human Papillomavirus and Related Diseases in the World. Summary Report 19 May 2017. [21 May 2017] http://www.hpvcentre.net/statistics/reports/XWX.pdf

5. Global cancer map. (2008). Retrieved September 20, 2016, from http://globalcancermap.com

6. Claeys, P., Gonzalez, C., Gonzalez, M., Page, H., Bello, R. E. \& Temmerman, M. (2002), Determinants of cervical cancer screening in a poor area: results of a population-based survey in Rivas, Nicaragua. Tropical Medicine \& International Health, 7: 935-941. http://doi.org/10.1046/j.1365-3156.2002.00953.x

7. Agurto, I., Bishop, A., Sánchez, G., Betancourt, Z., \& Roblesa, S. (2004). Perceived barriers and benefits to cervical cancer screening in Latin America. Preventive Medicine, 39(1), 91-98. https://doi.org/10.1016/j.ypmed.2004.03.040

8. Población total, estimada al 30 de junio del año 2012 (2012). Nicaragua: Gobierno de Reconcilación y Unidad Nacional. Retrieved October 9, 2016, from http://www.inide.gob.ni/estadisticas/Cifras\%20municipales\%20año\%202012\%20INIDE. $\underline{\mathrm{Pdf}}$

9. Katarzyna, J., Tomaszewski, K. A., Kamzol, W., Puskulluoglu, M., \& Krzemieniecki, K. (2014). Creating and field-testing the questionnaire for the assessment of knowledge about cervical cancer and its prevention among schoolgirls and female students. Journal of Gynecologic Oncology, 25(2), 81-89. https://doi.org/10.3802/jgo.2014.25.2.81

10. McRee, A. L., Brewer, N. T., Reiter, P. L., Gottlieb, S., \& Smith, J. S. (In press). The Carolina HPV Immunization Attitudes and Beliefs Scale (CHIAS): Scale development and associations with intentions to vaccinate. Sexually Transmitted Diseases. PMID: 19940807. https://doi.org/10.1371/journal.pone.0100193

11. Bradley, E. H., Curry, L. A., \& Devers, K. J. (2007). Qualitative Data Analysis for Health Services Research: Developing Taxonomy, Themes, and Theory. Health Services Research, 42(4), 1758-1772. http://doi.org/10.1111/j.1475-6773.2006.00684.x

12. Howe, S. L., Vargas, D. E., Granada, D., \& Smith, J. K. (2005). Cervical cancer prevention 
592

593

594

595

596

597

598

599

600

601

602

603

604

605

606

607

608

609

610

611

612

613

614

615

616

617

618

619

620

621

622

623

624

625

626

627

628

629

630

631

632

633

634

635 in remote rural Nicaragua: A program evaluation. Gynecologic Oncology, 99(3), 232235. http://dx.doi.org/10.1016/j.ygyno.2005.07.094

13. Wigle, J., Coast, E., \& Watson-Jones, D. (2013). Human papillomavirus (HPV) vaccine implementation in low and middle-income countries (LMICs): Health system experiences and prospects. Vaccine, 31(37), 3811-3817. http://doi.org/10.1016/j.vaccine.2013.06.016

14. Pan American Health Organization. Cervical Cancer Prevention and Control Programs: A rapid assessment in 12 countries of Latin America. Washington, D.C.: PAHO; 2010. http://www.paho.org/hq/index.php?option=com_docman\&task=doc_view\&gid=16119\&I temid $=270 \&$ lang $=$ en

15. Austin, L., T., Ahmad, F., McNally, M., \& Stewart, D., E. (2002). Breast and cervical cancer screening in hispanic women: A literature review using the health belief model. Women's Health Issues, 12(3), 122. https://doi.org/10.1016/S1049-3867(02)00132-9

16. Burak, L. J., \& Meyer, M. (1997). Using the health belief model to examine and predict college women's cervical cancer screening. Health Care For Women International, 18(3), 251. http://eds.a.ebscohost.com/ehost/detail/detail?vid=0\&sid=28f8eaed-453c-48f2-a017707c20ded8ee\%40sessionmgr4009\&bdata=JnNpdGU9ZWhvc3QtbGl2ZSZzY29wZT1za XRl\#AN=9706084117\&db=aph

17. Johnson, C., R., Mues, K., E., Mayne, S., L., \& Kiblawi, A., N. (2008). Cervical cancer screening among immigrants and ethnic minorities: A systematic review using the health belief model. Journal of Lower Genital Tract Disease, 12(3), 232. https://doi.org/10.1097/LGT.0b013e31815d8d88

18. Brisson, M., Jit, M., Boily, M., Laprise, J., Martin, D., Drolet, M., Alary, M., \& Benard, E. Modelling estimates of the incremental effectiveness \& cost-effectiveness of HPV vaccination. WHO Summary Report 2017. [1 July 2017]. http://www.who.int/immunization/sage/meetings/2016/october/07_Modelling_HPV_imm unization_strategies.pdf

19. Jones, C., L., Jensen, J., D., Scherr, C. L., Brown, N., R., Christy, K., \& Weaver, J. (2016). The health belief model as an explanatory framework in communication research: Exploring parallel, serial, and moderated mediation. Health Communication, 30(6), 566. https://doi.org/10.1080/10410236.2013.873363 
636 Appendix A. Quantitative questionnaire.

637

638 1. Location of survey:

639

640

641

642

643

644 4. Survey identification number:

645

646 5. How old are you? (years completed)

647

648 6. Describe the zone in which you live:

649 - Urban

650 - Rural

651

652 7. Highest educational level you have completed:

653 - No schooling

654 - Pre-school

655 - Some Primary School

656 - Primary School Complete

657 - Some Secondary School

658 - Secondary School Complete

659 - Some University

660 - University Completed

661 - Graduate Degree

662

663 8. How long does it take you to travel to the clinic (in minutes)?

664

665 9. Relationship/marital status:

666 - Single, never married

667 - Married or domestic partnership

668 - Divorced/Separated

669 - Widowed

670

671 10. Do you have private medical insurance?

$672-$ Yes

$673-\quad$ No

674

675 11. What type of work best represents your current situation?

676 - Government employee

677 - Non-government employee

678 - Self-employed

679 - Student

680 - Homemaker

$681 \quad-\quad$ Retired 


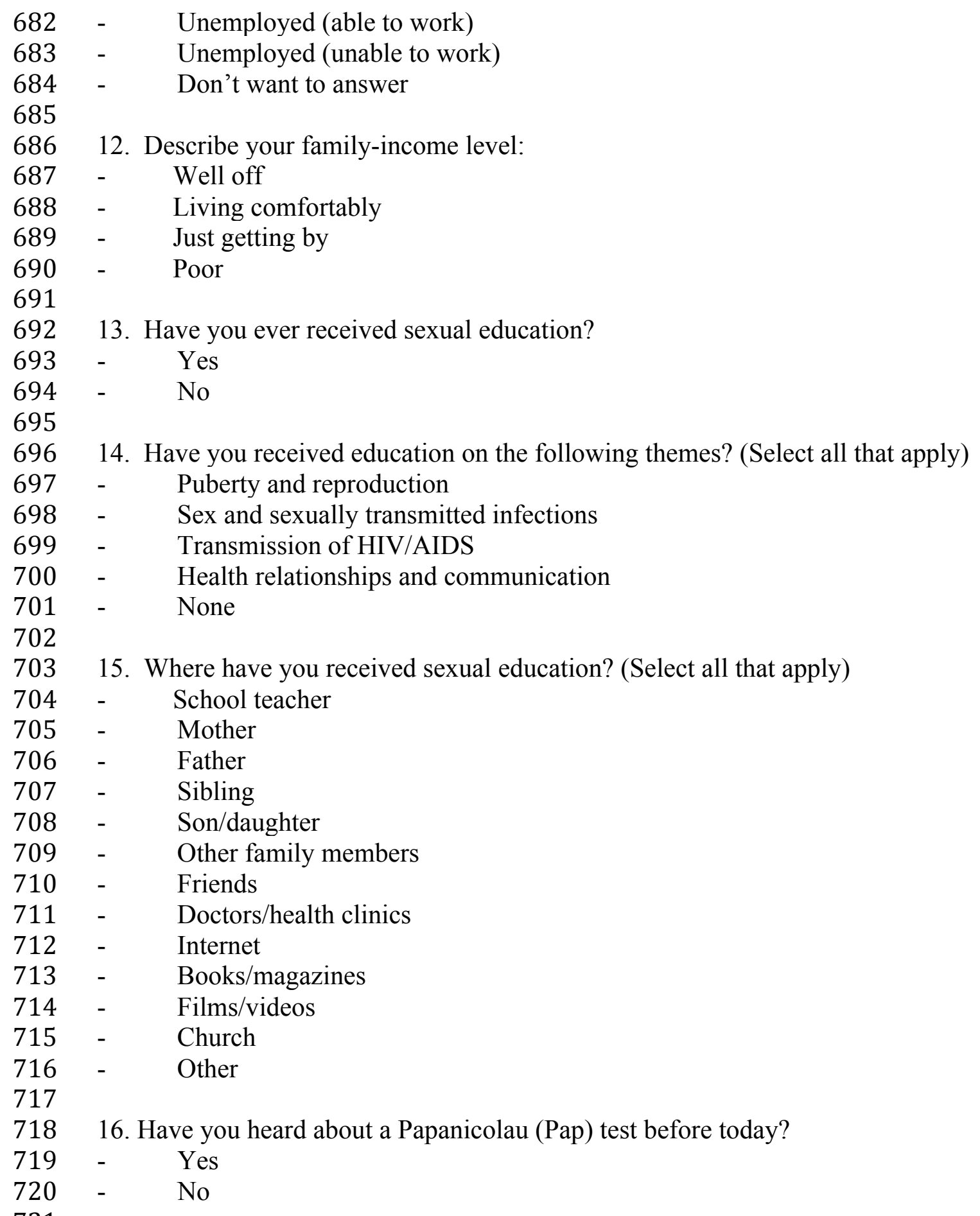

722 A Pap test is an exam of the anomalies of the cervix (below the uterus) that is performed during a 723 pelvic exam.

725 17. Have you had a Pap test before?

726 - Yes

$727 \quad-\quad$ No 
728 18. How old were you when you had your first Pap test?

729

730 19. How long ago was your most recent Pap test?

731 - Less than 3 months

$732 \quad$ - $\quad 3$ months to 6 months

$733 \quad$ - 6 months to 1 year

$734 \quad$ - 1 year to 2 years

$735 \quad-\quad 2$ years to 3 years

736 - 3 years or more

737 - Do not remember

739 20. How many days did it take to receive the results of your most recent Pap test?

740

741 21. Who performed your most recent Pap test?

742 - Female doctor

743 - Male doctor

744 - $\quad$ Female nurse

$745 \quad$ - $\quad$ Male nurse

746 - Female student

$747 \quad$ - $\quad$ Male student

749 22. How was the attitude of the person who performed your most recent Pap test? (Select all that

750 apply)

$751 \quad$ - Respectful

752 - Professional

$753 \quad-\quad$ Friendly

$754 \quad-\quad$ Expert

$755 \quad-\quad$ Nice

756 - Malicious

757 - Disrespectful

$758 \quad$ - Unprofessional

759 - Rude

760 - Inept

762 23. What was the result of your most recent Pap test?

763 - Positive (abnormal result)

$764 \quad$ - $\quad$ Negative (normal result)

765 - Undetermined

766 - $\quad$ Did not receive the results

767 - Do not remember

768

769 24. How many children do you have?

770

771 25. Have you been pregnant during the past three years or currently?

772 - Yes

773 - No 
774

775 26. Did you receive a Pap test during your most recent pregnancy?

$776 \quad-\quad$ Yes

$777 \quad-\quad$ No

$778 \quad$ - I don't know

779

780 27. How likely are you to get a Pap test in the next 3 years?

$781 \quad$ - Very unlikely

782 - Somewhat unlikely

783 - Somewhat likely

$784 \quad-\quad$ Very likely

785

786

787

28. What are reasons why you would be likely to get a Pap test in the next 3 years? (Select all that apply)

$788 \quad$ - $\quad$ Tests for cervical cancer

789 - $\quad$ Tests for HPV

$790 \quad$ - Improves sexual health

$791 \quad$ - Accessible at clinic

$792 \quad$ - $\quad$ Clinic is easily reached

793 - $\quad$ Promoted by doctors / nurses

794 - Improves prenatal health

795 - $\quad$ Recommended by friend

796 - Required by physician

797 - Other:

798

799 29. What are the requirements to have a Pap test? (Select all that apply)

800 - Not menstruating

801 - Not using a vaginal douche before exam

802 - $\quad$ Not applying vaginal cream, medication, or suppository before exam

803 - Not having intercourse three days before the exam

804 - $\quad$ There are no requirements

805

806 30. Have you ever been denied a Pap test?

$807 \quad-\quad$ Yes

808 - No

809

810 Do you agree or disagree with the following statements (\#31-52)?

811

812 31. Pap tests are painful

813 - $\quad$ Strongly agree

814 - $\quad$ Somewhat agree

815 - Somewhat disagree

816 - $\quad$ Strongly disagree

817

818

819 
820 32. Pap tests are safe

821 - $\quad$ Strongly agree

822 - Somewhat agree

823 - $\quad$ Somewhat disagree

824 - $\quad$ Strongly disagree

825

826 33. Pap tests can cause short-term discomfort

827 - $\quad$ Strongly agree

828 - $\quad$ Somewhat agree

829 - Somewhat disagree

830 - $\quad$ Strongly disagree

831

832 34. Pap tests can cause lasting health problems

833 - $\quad$ Strongly agree

834 - $\quad$ Somewhat agree

835 - Somewhat disagree

836 - $\quad$ Strongly disagree

837

838 35. Pap tests can increase likelihood of cervical cancer

839 - $\quad$ Strongly agree

840 - $\quad$ Somewhat agree

$841 \quad$ - $\quad$ Somewhat disagree

842 - $\quad$ Strongly disagree

843

844 36. You are unsure of the health benefits or purpose of Pap tests

845 - $\quad$ Strongly agree

846 - Somewhat agree

847 - $\quad$ Somewhat disagree

848 - $\quad$ Strongly disagree

849

850 37. Pap tests contradict with your religious beliefs.

$851 \quad$ - $\quad$ Strongly agree

852 - Somewhat agree

853 - Somewhat disagree

854 - $\quad$ Strongly disagree

855

856 38. Pap tests are too time-consuming

857 - $\quad$ Strongly agree

858 - Somewhat agree

859 - $\quad$ Somewhat disagree

860 - $\quad$ Strongly disagree

861

862 39. It takes a long time to receive the results of a Pap test

863 - Strongly agree

864 - Somewhat agree

865 - Somewhat disagree 


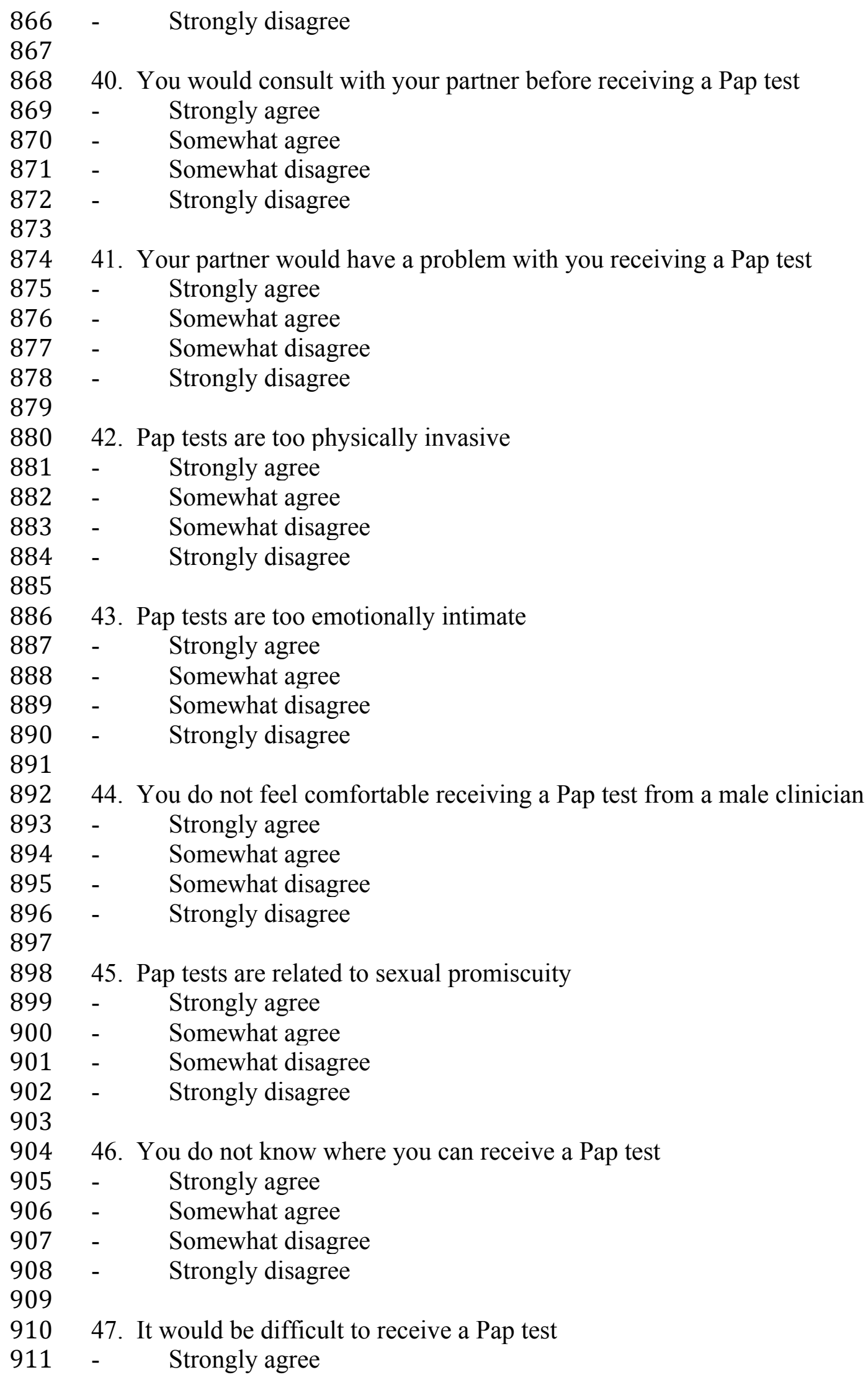




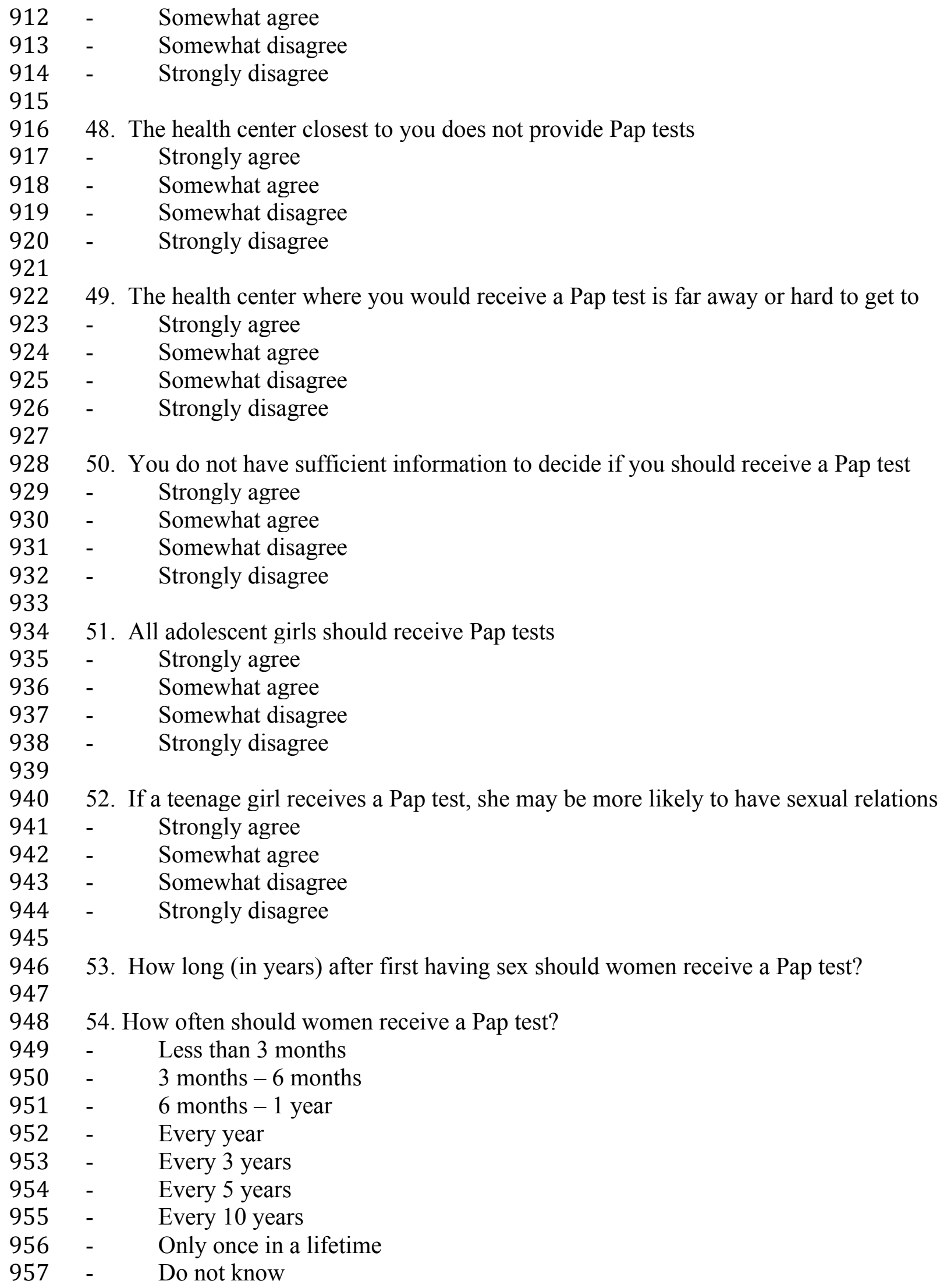


959 55. How much confidence do you have in Pap tests providing precise information about your 960 health? $(\%)$

961

962 56. Have you heard of human papillomavirus (HPV) before today?

$963 \quad-\quad$ Yes

$964 \quad-\quad$ No

965

966 57. Where have you received education about HPV? (Select all that apply)

967 - School

$968 \quad$ - Mother

969 - Father

970 - Brother / sister

971 - Son / daughter

$972 \quad$ - Other family members

973 - Friends

974 - Doctors / clinicians

975 - Internet

976 - Books / magazines

977 - Films / videos

978 - Church

979 - $\quad$ No education about HPV

980 - Other:

981

982 58. How probable do you believe it is for an individual to contract HPV during his or her

983 lifetime?

984 - Not at all probable

985 - Slightly probable

986 - Moderately probable

987 - Very probable

988

989 59. Can HPV cause cervical cancer?

$990 \quad-\quad$ Yes

$991 \quad-\quad$ No

$992 \quad-\quad$ Do not know

993

994 60. Is HPV is a sexually transmitted disease?

$995 \quad-\quad$ Yes

996 - No

997 - Do not know

998

999 61. Do you think HPV infection can go away without treatment?

1000 - Yes

1001 - No

1002 - Don't know

1003 
1004

1005 62. Can HPV be detected with a Pap test?

1006 - Yes

1007 - No

1008 - Do not know

1009

1010 63. With whom would you feel comfortable talking about HPV? (Select all that apply)

1011 - Someone at school

1012 - Mother

1013 - Father

1014 - Brother / sister

1015 - Son / daughter

1016 - Other family members

1017 - $\quad$ Friends

1018 - Female doctor

1019 - Male doctor

1020 - Someone you just met

1021 - Other:

1022

1023 64. Have you heard of cervical cancer before today?

1024 - Yes

1025 - No

1026

1027 65. Where have you received education about cervical cancer? (Select all that apply)

1028 - Internet

1029 - Television

$1030 \quad-\quad$ Film

1031 - Newspaper

1032 - Female doctors

1033 - Male doctors

1034 - Pamphlets

1035 - School

1036 - Family

1037 - Government programs

1038 - Programs of foreigners

1039 - Other:

1040 - $\quad$ Have not received education about cervical cancer

1041

1042

1043

1044 - No

1045 - Do not know

1046

1047 67. Is there an effective method that significantly reduces the risk of cervical cancer?

1048 - Yes

1049 - No 
1050 - Do not know

1051

1052 68. Have you had direct contact with cervical cancer (eg. you, or one of your family members or

1053 friends, have had the disease)?

1054 - Yes

1055 - No

1056 - Do not know

1057

1058 69. How likely do you think an average woman is to get cervical cancer?

1059 - Not at all probable

1060 - Slightly probable

1061 - Moderately probable

1062 - Very probable

1063

1064 70. Do you think cervical cancer could affect you in the future?

1065 - Yes

1066 - No

1067 - Do not know

1068

1069 71. If you were to have cervical cancer, how much would it affect your life?

1070 - Not at all

1071 - A little

1072 - Moderately

1073 - A lot

1074 - Do not know

1075

1076

1077

1078

1079

1080

72. What do you think is the relationship between the following factors and cervical cancer?

1081

Classify each factor using a scale of 1 to 6,1 meaning no relationship and 6 meaning a strong relationship.

1082 - Human immunodeficiency virus (HIV) infection

1083 - Multiple sexual partners

1084 - $\quad$ Early sexual initiation

1085 - $\quad$ History of sexually transmitted infections

1086 - Alcohol abuse

1087 - Smoking

1088 - Miscarriages and abortions

1089 - $\quad$ A large number of pregnancies and childbirths

1090 - $\quad$ Early initiation of menstruation

1091 - Use of condoms

1092 - Hormonal contraception

1093 - Breastfeeding

1094 - Use of drugs or psychoactive substances

1095 - Using public swimming pools 
1096

1097

1098

1099

1100

1101

1102

1103

1104

1105

1106

1107

1108

1109

1110

1111

1112

1113

1114

1115

1116

1117

1118

1119

1120

1121

1122

1123

1124

1125

1126

1127

1128

1129

1130

1131

1132

1133

1134

1135

1136

1137

1138

1139

1140 -

$1141-$

73. Do you think that the following factors can reduce the risk of cervical cancer? Classify each factor using a scale of 1 to 6,1 meaning no relationship and 6 meaning a strong relationship.

Diet rich in antioxidants

Regular physical exercise (more than daily activities)

Use of vitamin supplements

Proper long and relaxing sleep (minimum of 8 hours per night)

Avoiding highly processed food

Avoiding genetically modified food

Weight loss

Refraining from casual sex

74. How effective do you think Pap smears are in preventing and detecting cervical cancer?

\section{- $\quad$ Slightly}

- $\quad$ Moderately

- Very

- $\quad$ Extremely

- $\quad$ Do not know

75. With whom would you feel comfortable talking about cervical cancer? (Select all that apply)

- $\quad$ Someone at school

- Mother

- Father

- Brother / sister

- $\quad$ Son / daughter

- $\quad$ Other family members

- $\quad$ Friends

- $\quad$ Female doctor

- $\quad$ Male doctor

- $\quad$ Someone you just met

- Other:

76. Have you heard about the vaccine against HPV and cervical cancer?

- Yes

- No

77. Have you ever heard about the HPV vaccine from any of these sources? (Select all that apply)

Health care provider

- $\quad$ Friend or family member

- $\quad$ Pamphlet or poster

- Commercial or advertisement of a drug company

- $\quad$ Television (not as an ad from a drug company; eg. through a news story)

- Radio

- Internet

- Newspaper 


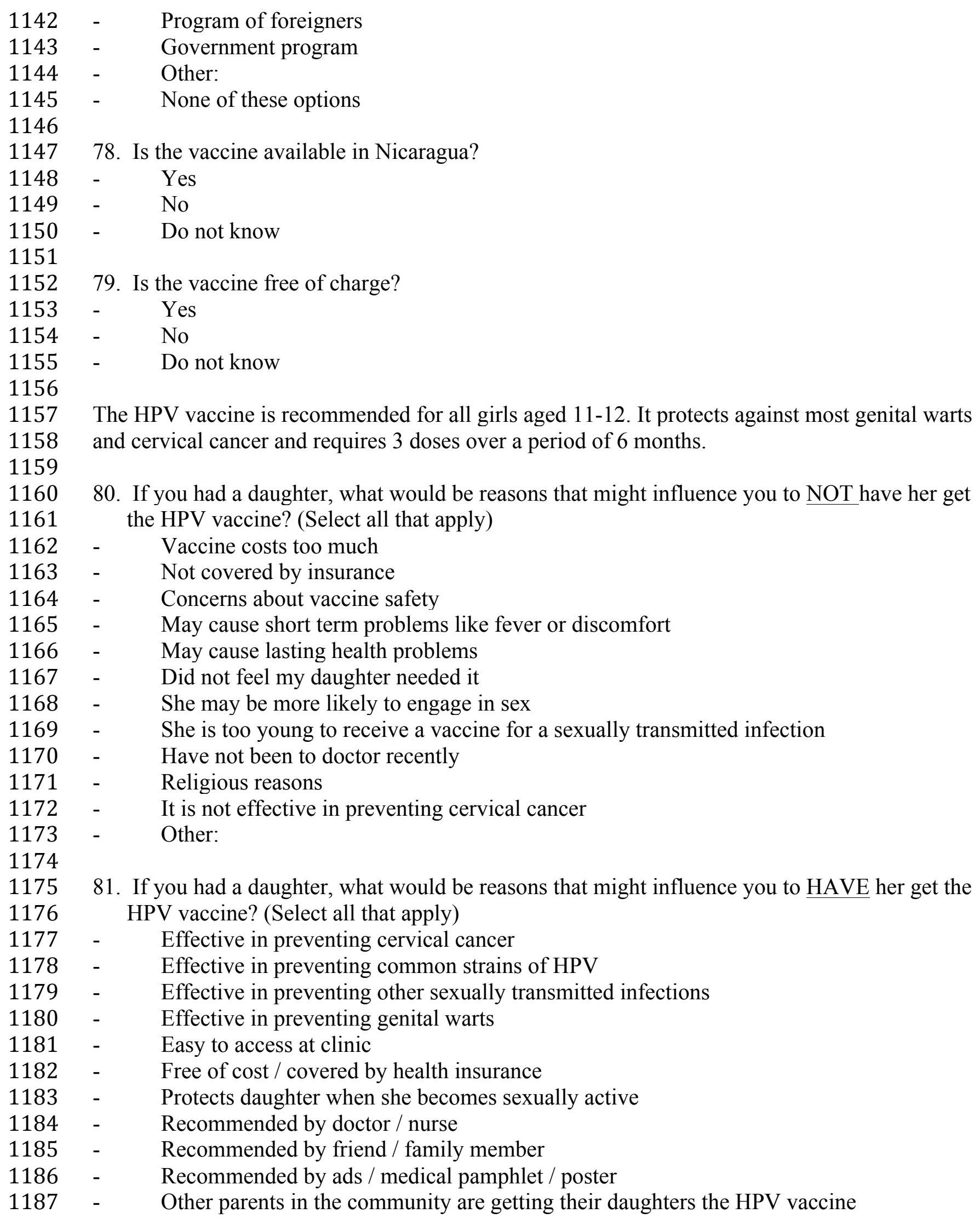


1188 - Other:

1189

1190 82. If the vaccine were completely free and available, how likely would you be to get the HPV

1191 vaccine for her in the next year?

1192 - Definitely would not

1193 - Probably would not

1194 - Probably would

1195 - Definitely would

1196

1197

83. How effective do you think the HPV vaccine is in preventing cervical cancer?

1198 - Slightly effective

1199 - $\quad$ Moderately effective

1200 - Very effective

1201 - $\quad$ Extremely effective

1202

1203

1204

1205

1206

1207

1208

1209

1210

1211

1212

1213

1214

1215

1216

1217

1218

1219

1220 
1221 Appendix B. Survey items included in the belief and knowledge scores.

\begin{tabular}{|l|l|}
\hline \multicolumn{2}{|l|}{ Survey items included in belief score: } \\
\hline 1. & Pap tests are painful. \\
\hline 2. & Pap tests are safe. \\
\hline 3. & Pap tests can cause short-term discomfort. \\
\hline 4. & Pap tests can cause lasting health problems. \\
\hline 5. & Pap tests can increase likelihood of cervical cancer. \\
\hline 6. & Pap tests contradict with your religious beliefs. \\
\hline 7. & Pap tests are too time-consuming. \\
\hline 8. & It takes a long time to receive the results of a Pap test. \\
\hline 9. & Your partner would have a problem with you receiving a Pap test. \\
\hline 10. & Pap tests are too physically invasive. \\
\hline 11. & Pap tests are too emotionally intimate. \\
\hline 12. & You do not feel comfortable receiving a Pap test from a male clinician. \\
\hline 13. & Pap tests are related to sexual promiscuity. \\
\hline 14. & It would be difficult to receive a Pap test. \\
\hline 15. & All adolescent girls should receive Pap tests. \\
\hline 16. & If a teenage girl receives a Pap test, she may be more likely to have sexual relations. \\
\hline 17. & How long (in years) after first having sex should women receive a Pap test? \\
\hline 18. & How often should women receive a Pap test? \\
\hline 19. & How likely do you think an average woman is to get cervical cancer? \\
\hline 20. & Do you think cervical cancer could affect you in the future? \\
\hline 21. & If you were to have cervical cancer, how much would it affect your life? \\
\hline 22. & How effective do you think Pap smears are in preventing and detecting cervical cancer? \\
\hline
\end{tabular}

\begin{tabular}{|l|l|}
\hline \multicolumn{2}{|l|}{ Survey items included in knowledge score: } \\
\hline 1. & What are the requirements to have a Pap test? \\
\hline 2. & You do not know where you can receive a Pap test \\
\hline 3. & How likely is it to contract HPV? \\
\hline 4. & Can HPV cause cervical cancer? \\
\hline $\mathbf{5 .}$ & Is HPV is a sexually transmitted disease? \\
\hline 6. & Do you think HPV infection can go away without treatment? \\
\hline 7. & Can HPV be detected with a Pap test? \\
\hline 8. & Can cervical cancer be a terminal illness (or can you die from cervical cancer)? \\
\hline 9. & Is there an effective method that significantly reduces the risk of cervical cancer? \\
\hline
\end{tabular}


1228 Appendix C. Discussion guide for semi-structured, qualitative interviews.

1229

1230

1231

1232

1233

1234

1235

1236

1237

1238

1239

1240

1241

1242

1243

1244

1245

1246

1247

1248

1249

1250

1251

1252

1253

1254

1255

1256

1257

1258

1259

1260

1261

1262

1263

1264

1265

1. Tell me about your experience with health care.

a. Do you usually come to this health center?

b. Do you live in an urban or rural area?

2. Tell me about your experience with sexual health education.

a. Where can women receive sexual health education?

b. Do you want to receive more sexual health education?

c. Do you think that adolescents today have sufficient information about sexual health?

d. How could the sexual education of girls and women be improved?

3. Have you ever had a Pap smear before?

a. What was the context? - Why? When? Who performed it? What was the purpose of the test?

b. What are your concerns with the Pap test?

c. Do you feel physically and emotionally comfortable receiving a Pap?

d. Do you feel comfortable having a Pap performed by a male clinician? Why?

e. How confident are you that a Pap provides precise information about your health?

f. What is the relation between sexual promiscuity and the Pap test?

4. What are your concerns regarding your sexual health?

5. Have you heard of human papillomavirus (HPV)?

a. What is your perceived risk of contracting the virus?

b. What do you think is the general knowledge and attitude of the community towards HPV?

6. Have you had experiences with cervical cancer before (personally, family, or friend affected by the disease)?

a. If you could change part of your/her experience with cancer, what would you change?

b. What do you think when you hear the word cancer?

c. How is the knowledge and attitude of the community toward cervical cancer?

d. Who do you feel comfortable speaking with about HPV and cervical cancer?

e. Have you spoken with your daughters and/or sons about these themes?

7. How do you make decisions regarding your health?

a. With whom do you speak?

b. What do you do to maintain your health and security against sexually transmitted infections?

c. How worried are you about contracting a sexually transmitted infection?

8. Have you heard of the HPV vaccine?

a. If the vaccine were to be available and free, how likely are you to give the vaccine to your children? Why? 


\section{Figure 1 (on next page)}

Response rate and final yield of the quantitative sample. 


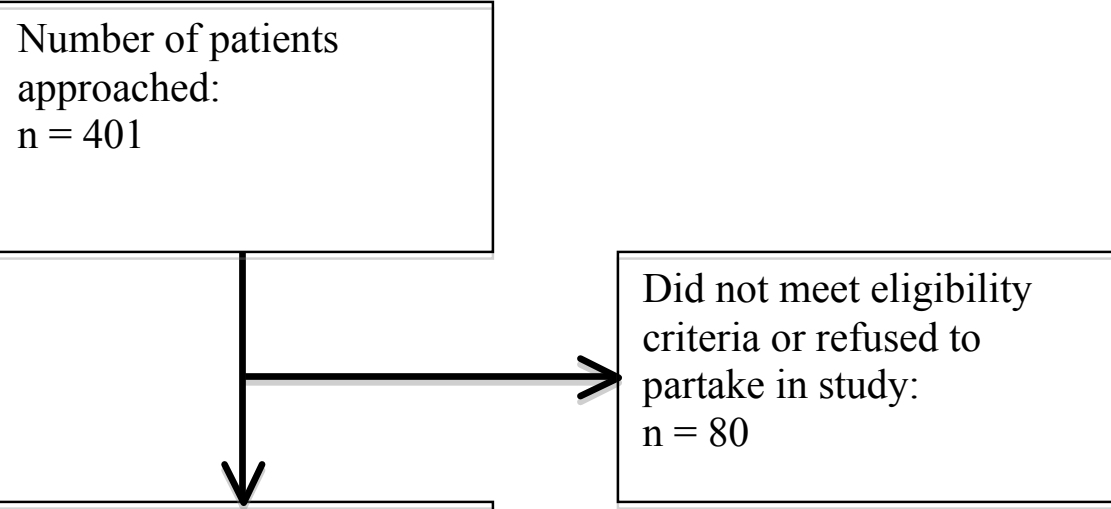

Number of initiated surveys:

$\mathrm{n}=321$

Response rate: $80 \%$

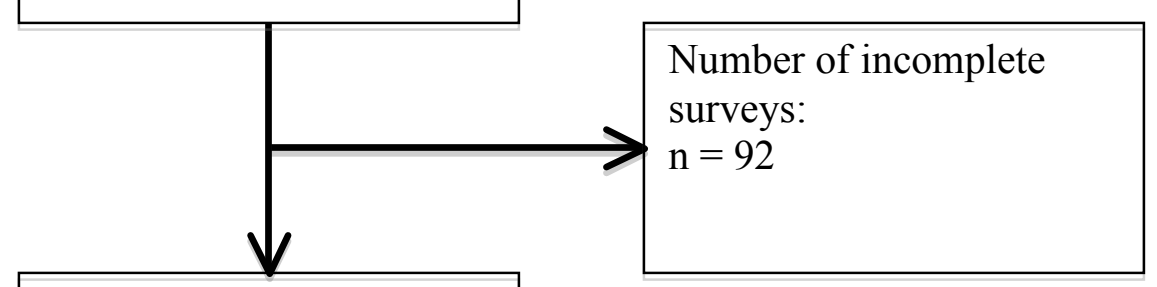

Number of completed

surveys:

$\mathrm{n}=229$

Final yield: $\mathbf{5 7 \%}$ 


\section{Table 1 (on next page)}

Quantitative sample characteristics ( $n=229)$ 


\begin{tabular}{|c|c|c|c|}
\hline Demographic characteristic: & $\begin{array}{r}\text { Total }(\mathbf{n}=\mathbf{2 2 9}) \\
\mathrm{n}(\%)\end{array}$ & $\begin{array}{r}\text { Urban }(\mathbf{n}=117) \\
\mathrm{n}(\%)\end{array}$ & $\begin{array}{r}\text { Rural (n=112) } \\
n(\%)\end{array}$ \\
\hline Mean age & 28.1 & 28.6 & 27.6 \\
\hline \multicolumn{4}{|l|}{ Education } \\
\hline No formal education & $13(5.68)$ & $2(1.71)$ & $11(9.82)$ \\
\hline Primary school* & $54(23.58)$ & $16(13.68)$ & $38(33.93)$ \\
\hline Secondary school* & $105(45.85)$ & $56(47.86)$ & $49(43.75)$ \\
\hline University* & $53(23.14)$ & $40(34.19)$ & $13(11.61)$ \\
\hline Postgraduate & $4(1.75)$ & $3(2.56)$ & $1(0.89)$ \\
\hline \multicolumn{4}{|l|}{ Marital Status } \\
\hline Single, never married & $63(27.51)$ & $38(32.48)$ & $25(22.32)$ \\
\hline Married or domestic partnership & $158(69.00)$ & $72(61.54)$ & $86(76.79)$ \\
\hline Divorced or separated & $6(2.62)$ & $5(4.27)$ & $1(0.89)$ \\
\hline Widowed & $2(0.87)$ & $2(1.71)$ & $0(0.00)$ \\
\hline \multicolumn{4}{|l|}{ Health Insurance Status } \\
\hline Insured & $25(10.92)$ & $15(12.82)$ & $10(8.93)$ \\
\hline Uninsured & $204(89.08)$ & $102(87.18)$ & $102(91.07)$ \\
\hline \multicolumn{4}{|l|}{ Income Level } \\
\hline Wealthy & $4(1.75)$ & $3(2.56)$ & $1(0.89)$ \\
\hline Living comfortably & $35(15.28)$ & $22(18.80)$ & $13(11.61)$ \\
\hline Just getting by & $120(52.40)$ & $61(52.14)$ & $59(52.68)$ \\
\hline Poor & $70(30.57)$ & $31(26.50)$ & $39(34.82)$ \\
\hline Mean travel time to health center (min) & 22.9 & 19.3 & 26.6 \\
\hline \multicolumn{4}{|l|}{ Have you ever received a Pap smear? } \\
\hline Yes & $203(88.65)$ & $100(85.47)$ & $103(91.96)$ \\
\hline No & $26(11.35)$ & $17(14.53)$ & $9(8.04)$ \\
\hline
\end{tabular}

*Some or complete 


\section{Table 2 (on next page)}

Time elapsed since last Pap test $(n=203)^{*}$ 


\begin{tabular}{|l|l|l|l|}
\hline & Total $(\mathbf{n}=\mathbf{2 0 3})^{*}$ & Urban $(\mathbf{n}=\mathbf{1 0 0})$ & Rural $(\mathbf{n}=\mathbf{1 0 3})$ \\
\hline Time & $\mathbf{n}(\mathbf{\%})$ & $\mathbf{n}(\mathbf{\%})$ & $\mathbf{n}(\mathbf{\%})$ \\
\hline Less than 3 months & $76(37.44)$ & $40(40.00)$ & $36(34.95)$ \\
\hline 3 to 6 months & $37(18.23)$ & $15(15.00)$ & $22(21.36)$ \\
\hline 6 months to 1 year & $50(24.63)$ & $29(29.00)$ & $21(20.39)$ \\
\hline 1 to 2 years & $25(12.32)$ & $9(9.00)$ & $16(15.53)$ \\
\hline 2 to 3 years & $5(2.46)$ & $3(3.00)$ & $2(1.94)$ \\
\hline 3 years or more & $9(4.43)$ & $3(3.00)$ & $6(5.83)$ \\
\hline Not sure & $1(0.49)$ & $1(1.00)$ & $0(0.00)$ \\
\hline
\end{tabular}

*26 incomplete responses for survey item 
Table 3 (on next page)

Belief frequencies regarding Pap tests and HPV vaccine $(n=229)$ 


\begin{tabular}{|l|l|l|l|l|l|l|}
\hline & \multicolumn{2}{|c|}{ Total (n= 229) } & \multicolumn{2}{c|}{ Urban (n= 117) } & \multicolumn{2}{c|}{ Rural (n = 112) } \\
\hline Belief & $\begin{array}{l}\text { Agree } \\
\text { n (\%) }\end{array}$ & $\begin{array}{l}\text { Disagree } \\
\text { n (\%) }\end{array}$ & $\begin{array}{l}\text { Agree } \\
\text { n (\%) }\end{array}$ & $\begin{array}{l}\text { Disagree } \\
\text { n (\%) }\end{array}$ & $\begin{array}{l}\text { Agree } \\
\text { n (\%) }\end{array}$ & $\begin{array}{l}\text { Disagree } \\
\text { n (\%) }\end{array}$ \\
\hline $\begin{array}{l}\text { Not } \\
\text { comfortable } \\
\text { receiving Pap } \\
\text { from male } \\
\text { provider }\end{array}$ & $161(70.31)$ & $68(29.69)$ & $78(66.67)$ & $39(33.33)$ & $83(74.11)$ & $29(25.89)$ \\
\hline $\begin{array}{l}\text { Teenage pap } \\
\text { recipient } \\
\text { more likely to } \\
\text { have sex }\end{array}$ & $123(53.71)$ & $106(46.29)$ & $52(44.44)$ & $65(55.56)$ & $71(63.39)$ & $41(36.61)$ \\
\hline $\begin{array}{l}\text { Unsure of } \\
\text { health } \\
\text { benefits or } \\
\text { purpose of } \\
\text { Pap test }\end{array}$ & $59(25.76)$ & $170(74.24)$ & $35(29.91)$ & $82(70.09)$ & $24(21.43)$ & $88(78.57)$ \\
\hline $\begin{array}{l}\text { Takes a long } \\
\text { time to } \\
\text { receive results } \\
\text { from Pap test }\end{array}$ & $145(63.32)$ & $84(36.68)$ & $78(66.67)$ & $39(33.33)$ & $67(59.82)$ & $45(40.18)$ \\
\hline $\begin{array}{l}\text { Likely to give } \\
\text { daughter HPV } \\
\text { vaccine if free }\end{array}$ & $224(97.82)$ & $5(2.18)$ & $114(97.44)$ & $3(2.56)$ & $110(98.21)$ & $2(1.79)$ \\
\hline
\end{tabular}




\section{Table 4(on next page)}

Influence of variables on screening promoting-beliefs $(n=229)$ 


\begin{tabular}{|l|l|l|}
\hline \multicolumn{2}{|c|}{ Impact on belief score: coefficient (confidence interval)**1,2 } \\
\hline Variable Name & Unadjusted & Adjusted \\
\hline Urban vs. rural & $-0.23(-1.20,0.73)$ & $0.63(-0.38,1.63)$ \\
\hline Cervical cancer contact & $0.43(-0.75,1.61)$ & $-0.13(-1.17,0.91)$ \\
\hline Age & $0.03(-0.03,0.10)$ & $0.03(-0.03,0.09)$ \\
\hline Knowledge & $0.81(0.59,1.02)^{* * *}$ & $0.73(0.47,1.00) * * *$ \\
\hline Education & - & \\
\hline No formal education & - & $-0.98(-6.55,4.60)$ \\
\hline Primary school* & - & $1.11(-4.14,6.35)$ \\
\hline Secondary school* & - & $1.25(-3.83,6.34)$ \\
\hline University* & - & $1.92(-3.09,6.93)$ \\
\hline Postgraduate & - & REF \\
\hline Income & - & $0.81(-3.53,5.14)$ \\
\hline Rich & - & REF \\
\hline Living comfortably & - & $0.20(-1.05,1.44)$ \\
\hline Just getting by & - & $-0.12(-1.60,1.37)$ \\
\hline Poor & - & \\
\hline Some or complete, $* * 95 \%$ CI, $* * * p<0.001$ & - \\
\hline
\end{tabular}

1 The belief score is a summation of 22 survey questions that assessed participants' beliefs regarding physical and emotional discomfort associated with Pap smears, perceived safety of the exam, the amount of time it takes to receive the exam and results, the relationship between Pap smears and sexual promiscuity, frequency of screening, comfort receiving a Pap from a male clinician, and perceived likelihood of being affected by cervical cancer in the future.

2 To determine the correlates of the belief score, unadjusted analyses were conducted using simple linear regressions and adjusted analysis using a multiple linear regression. 